\title{
Carotid Endarterectomy for Radiation-induced Carotid Artery Stenosis
}

\section{-Case Report-}

\author{
Kyoko NisHI, Masaaki UnO, Shin UEdA, Kazutoshi NISHITANI, \\ Kiyohito SHINNO, Shinji NAGAHIRO, Hidehisa HORIGUCHI*, \\ and Toshiaki SANO*
}

Departments of Neurological Surgery and *Pathology, School of Medicine, The University of Tokushima, Tokushima

\begin{abstract}
A 60-year-old male presented with radiation-induced left carotid artery stenosis. Carotid endarterectomy was performed successfully without postoperative deficits. Carotid endarterectomy is the therapeutic management of choice for these lesions.
\end{abstract}

Key words: radiation, carotid artery stenosis, carotid endarterectomy

\section{Introduction}

The natural history of vascular disease induced by radiation therapy is still unknown. However, carotid artery stenosis and cerebral stroke frequently occurs following irradiation., ${ }^{5,6,10-12,14,20)}$ Symptoms may appear 3 months to 30 years after radiation therapy. ${ }^{12}$ Carotid endarterectomy (CEA) was previously performed in seven patients with radiation-induced carotid artery stenosis among 2527 CEA procedures between 1970 and $1987 .{ }^{2)}$ We report a case of radiation-induced carotid artery stenosis treated by CEA, our first such experience among 268 CEAs performed between 1975 and 1996.

\section{Case Report}

A 60-year-old male suffered right hemiparesis which disappeared within 30 minutes on March 3, 1996. He suffered another right transient ischemic attack on March 31, 1996 and was transferred to our hospital for treatment of carotid artery stenosis. He had received radiation therapy ( $50 \mathrm{~Gy}$ ) for an adenoid cystic carcinoma in the left neck 15 years previously.

On admission, he was alert and showed no neurological deficits except left carotid bruit. He had no

Received May 6, 1997; Accepted August 5, 1997 history of hypertension and diabetes mellitus. He was taking oral medication for hyperlipidemia, but blood chemistry examination showed that the total cholesterol level was $158 \mathrm{mg} / \mathrm{dl}$.

Magnetic resonance imaging demonstrated cerebral infarction in the left precentral area (Fig. 1). Left carotid angiography showed severe and longsegmental carotid artery stenosis with ulcer formation, located between the C-6 and C-2 levels where radiation therapy had been carried out (Fig. 2). Right carotid and vertebral angiography showed no
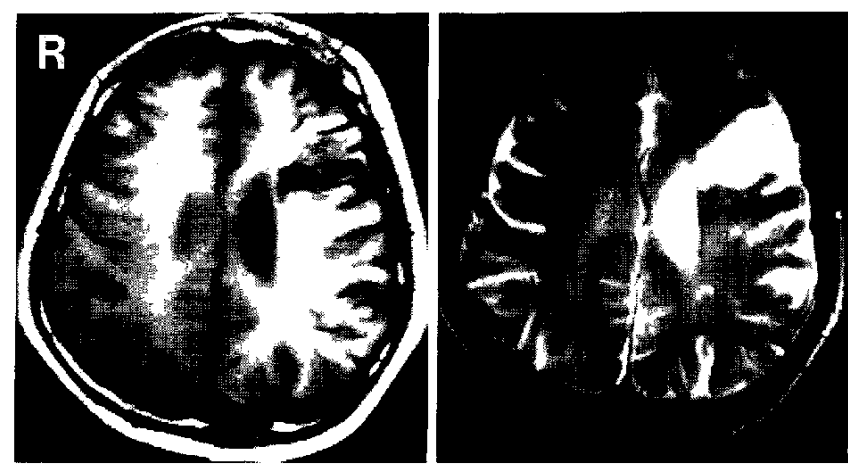

Fig. $1 \mathrm{~T}_{1}$-weighted (Ieft) and $\mathrm{T}_{2}$-weighted (right) magnetic resonance images showing cerebral infarction in the left precentral area. 


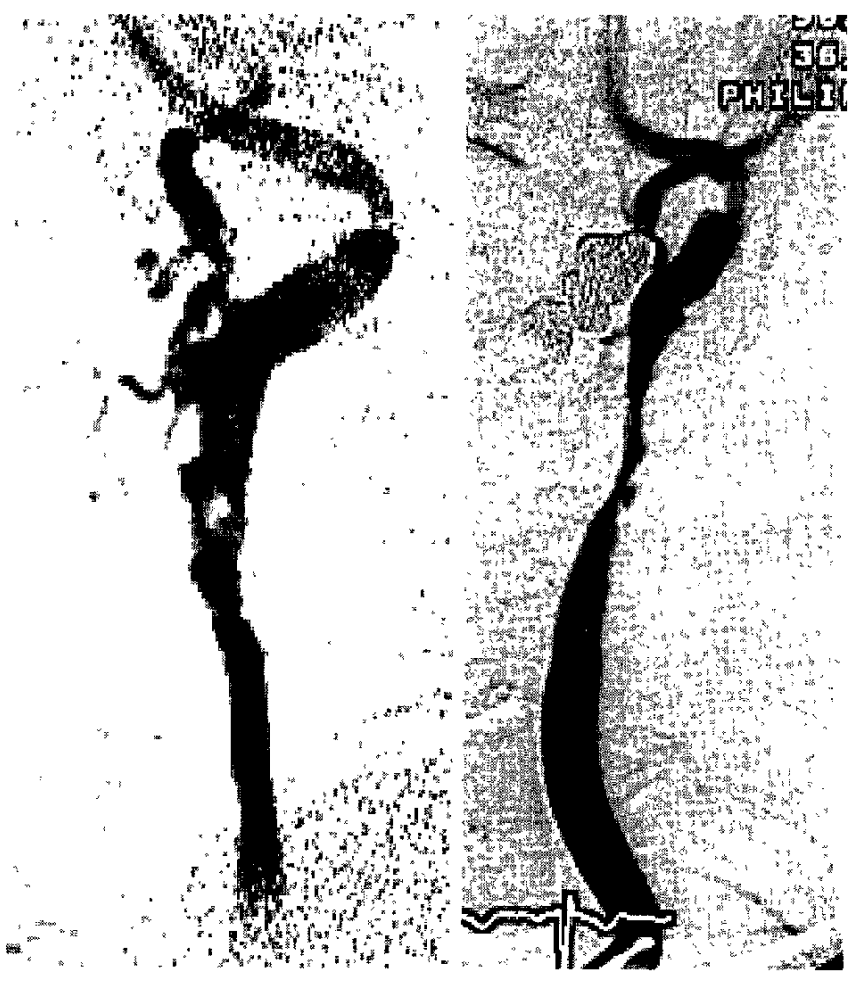

Fig. 2 Preoperative left carotid angiograms, lateral (left) and anteroposterior (right) views, showing severe long-segmental carotid artery stenosis.

atherosclerotic lesions except stenosis of the right internal carotid artery (ICA) (50\%) in the petrous portion. Coronary angiography indicated no atherosclerosis in his coronary arteries. Single photon emission computed tomography using $740 \mathrm{MBq}$ technetium-99m-labeled d,l-hexamethylpropyleneamine oxime revealed defects in the left frontotemporal lobe.

CEA was performed to remove the source of possible embolisms and increase his сегеbral blood flow on June 11, 1996. Under general anesthesia, the patient was placed in the supine position with his head extended and turned away from the side to be operated on. The skin in the left neck was atrophic and the subcutaneous connecting tissue was fibrotic. However, dissection of this portion was not difficult. The internal jugular vein (IJV) was cut temporally because it was located just on the left common carotid artery (CCA). The left ICA was carefully dissected and a tourniquet for the ICA was placed on the distal side of the hypoglossal nerve to make removal of the distal side of plaque easier. Thickened vagus nerve was present on the left ICA and CCA, and was dissected free. An intraoperative ICA occlusion test carried out for 3 minutes indicated

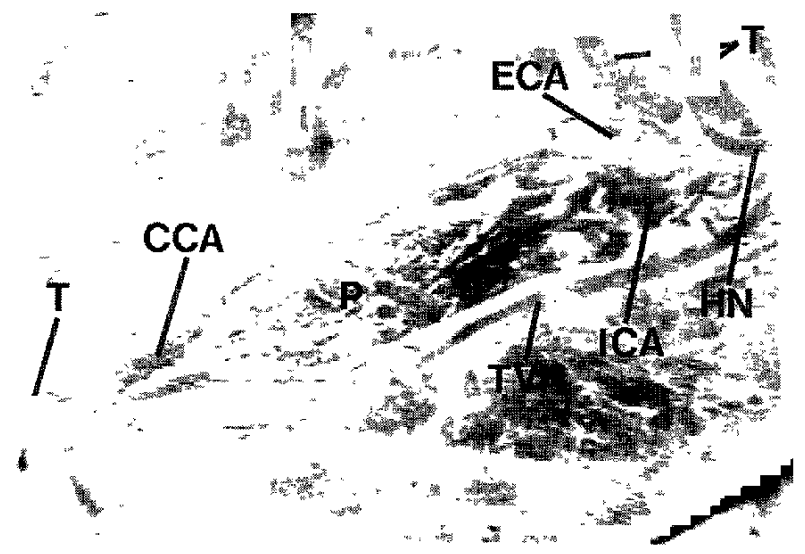

Fig. 3 Photograph showing the surgical field after arteriotomy from the common carotid artery (CCA) to internal carotid artery (ICA), and plaque (P) combining long-segmental, dirty, and yellow debris. ECA: external carotid artery, HN: hypoglossal nerve, $T$ : tourniquet, TVN: thickened vagus nerve.

no significant change in electroencephalography. Therefore, the arterial wall from the CCA to the ICA was cut without an internal shunt. Gray dirty plaque was distended to the proximal side of the CCA. The CCA was then cut more proximally with an extension of the skin incision and cutting of the omohyoid muscle. In the intraoperative macroscopic view, intact adventitia of the CCA was seen. However, the tunica media and plaque were fused forming yellow debris and thus both components were indistinguishable, especially on the distal side, and plaque was very difficult to remove at this site (Fig. $3)$. Two tacking sutures were placed just distal to the site of the ICA plaque in order to avoid intimal flap formation. The length of the CEA was $13 \mathrm{~cm}$. The left carotid artery was closed with a vein patch graft (saphenous vein) and the IJV was reconstructed using a GORE-TEX graft.

HE staining of the resected specimen showed remarkable thickening of smooth muscle layers and numerous lipids, cholesterin crystals, and macrophages were seen above and within smooth muscle layer (Fig. 4). These changes were recognized from the proximal to distal side. Endothelial proliferation was not seen in the specimen. Neoangiogenesis or intramural hemorrhage was not seen. Azan-Mallory stain revealed obvious fibrosis in the media.

Postoperatively he developed no neurological deficit and did well during the postoperative course. Carotid angiography demonstrated good patency and disappearance of the carotid artery stenosis except for a mild notch just distal to the end of the CEA 


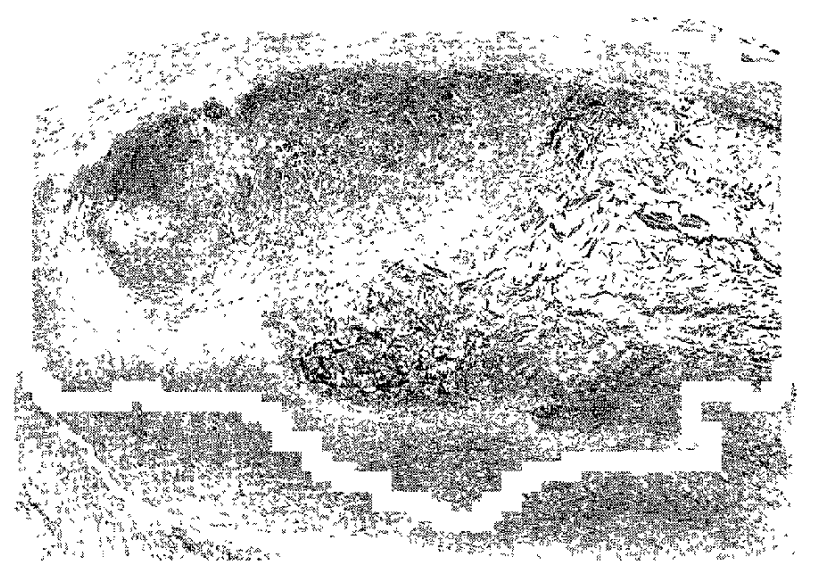

Fig. 4 Photomicrograph of the removed plaque showing the atheromatous plaque consisted of atheroma with numerous cholesterin crystals and cell debris and an overlying fibrosis capsule. Plaque involved the media seen in the top of the photograph. HE stain, $\times 35$.

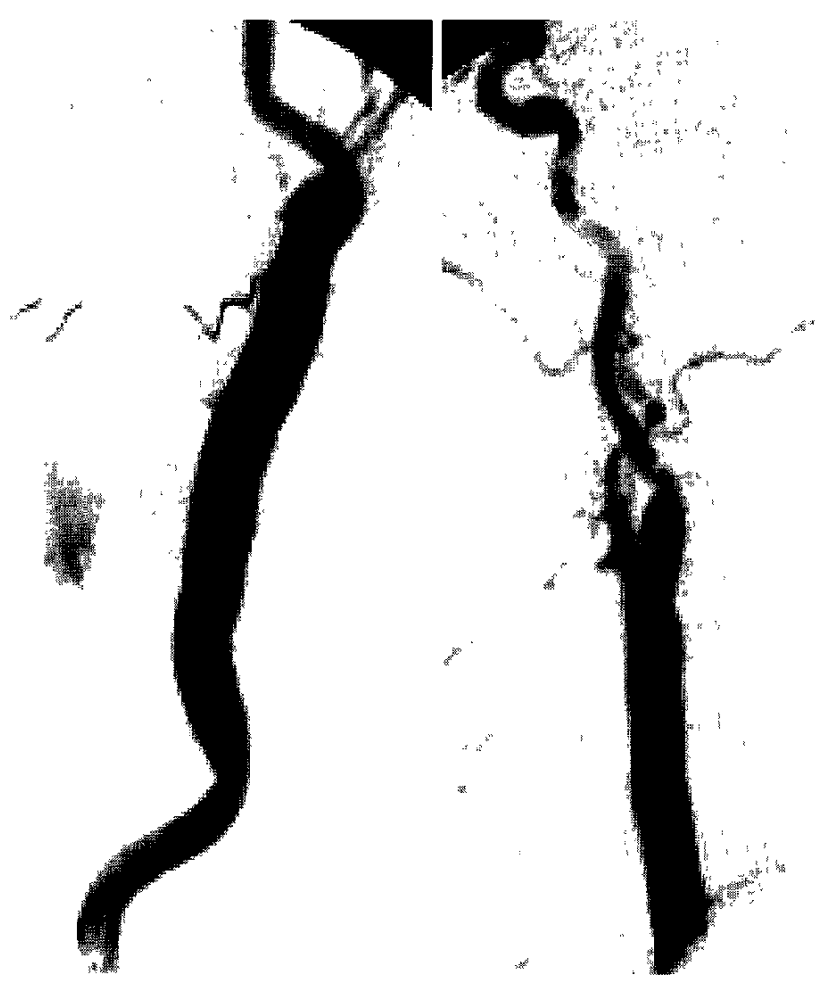

Fig. 5 Postoperative left carotid angiograms, anteroposterior (left) and lateral (right) views, showing good patency of the left carotid artery.

(Fig. 5). He was discharged and returned to work.

\section{Discussion}

A $6.3 \%$ incidence of stroke was found in 910 patients who had undergone radiation therapy for Hodgkin's lymphoma, non-Hodgkin's lymphoma, and head and neck cancers. ${ }^{\text {bl }}$ Prospective evaluation of 118 patients with carotid artery stenosis for a 9year period found that carotid duplex imaging was abnormal in $25 \%$ of patients who had undergone radiation therapy but in only $6.4 \%$ of non-irradiated patients. ${ }^{\text {i) }}$ Carotid duplex imaging found moderateto-severe stenosis in $30 \%$ of 53 irradiated patients followed for an average period of 28 months, ${ }^{15)}$ a fivefold higher incidence of stenosis than observed in a non-irradiated group. Flow mapping found a $5 \%$ incidence of $40 \%$ or greater stenosis among 102 unselected patients. ${ }^{17}$ Duplex scanning of patients who had not undergone irradiation found $2.5 \%$ incidence of $50 \%$ or greater stenosis among 348 unselected patients at health fairs. ${ }^{4}$

The concept of radiation-induced atheromatous disease was introduced by Silverberg et al. ${ }^{20]}$ whose patients had less evidence of coronary and peripheral vascular disease, compared to a control group with atheromatous disease. In our case, there was no severe atherosclerotic change in the intracranial and coronary arteries, although the left carotid artery showed severe stenosis, due to previous radiation therapy.

Skin atrophy and fibrosis of the subcutaneous tissue in the irradiated area is another characteristic change. Such skin changes and plaque change occurred in the carotid artery in seven patients treated by CEA. ${ }^{23}$ The intimal plaque of these patients was very thick, frequently quite long, and formed in an artery where all layers were adherent. These characteristics make CEA more difficult to perform than normal. ${ }^{2,211}$ Tacking sutures were often required at the distal end of the plaque to avoid an embolic source or dissection. However, if the adventitia became very thin after CEA, we consider an interposition from the CCA to ICA by a saphenous vein graft or a synthetic graft.

Our patient had skin atrophy and fibrosis of the subcutaneous tissues, and dissection of the proximal side of the ICA was difficult. The intimal plaque was dirty and irregular compared to the usual atheromatous plaque. However, there was no significant change in the histological findings compared to atherosclerotic plaque. The histological findings in radiation-induced vascular disease include early post-radiation changes, which generally spare large, elastic vessels, such as the CCA, but induce sloughing and nuclear disruption of endothelial cells, deposition of platelets with thrombosis, intimal prolifera- 
tion, necrosis, fragmentation of the elastic lamina, hyaline thickening, and production of collagen. ${ }^{2,3,7,8,18,19)}$ With time, the large elastic vessels undergo degeneration of the media with resultant necrosis and chronic inflammation. The intima overlying areas of medial necrosis develops atherosclerotic lesions, presumably accounting for the atypical distribution of plaque found in radiationinduced carotid artery stenosis. Arterial medial degeneration may be a secondary effect of occlusive vasculopathy within the vasa vasorum, which is primarily injured by irradiation. ${ }^{2,18]}$

CEA is recommended for patients with radiationinduced carotid artery stenosis, despite the technical difficulties, and can achieve successful treatment and good clinical results. ${ }^{2)}$ Postoperative follow-up of mean 49 months of nine CEA procedures found one patient suffered transient ischemic attack, who had received anticoagulation therapy, and two patients with transient lower cranial nerve paresis, but all patients recovered well. ${ }^{2)}$ Mortality and morbidity of CEA for such patients is still acceptable compared with the technical difficulty. ${ }^{14,20}$ )

Recently, carotid angioplasty has also been performed and achieved a good clinical outcome. ${ }^{1,9,13,16,22,23)}$ However, complications associated with this method such as distal embolisms and rupture of the vessel walls have been demonstrated. In our case, the radiation-induced carotid artery stenosis had a dirty and irregular surface. Moreover, the carotid artery stenosis was extensive. Therefore, it is very difficult not only to protect distal embolism but also to improve long stenosis by carotid angioplasty. We consider that CEA is optimum for patients with carotid artery stenosis with long-segmental and dirty plaque. The indications for angioplasty in these patients should be limited.

\section{References}

1) Ahaja A, Blatt GL, Guterman LR, Hopkins LN: Angioplasty for symptomatic radiation-induced extracranial carotid artery stenosis; Case report. Neurosurgery 36: 399-403, 1995

2) Atkinson JLD, Sundt TM Jr, Dale AJD, Cascino TL, Nichols DA: Radiation-associated atheromatous disease of the cervical carotid artery: Report of seven cases and review of the literature. Neurosurgery 24: 171-178, 1989

3) Byhardt RW, Moss WT: The heart and blood vessels, in Moss WT, Cox JD (eds): Radiation Oncology, ed 6. Rationale, Technique, Results. St Louis, CV Mosby, 1989, pp 277-284

4) Colgan MP, Strode GR, Sommer JD, Gibbs JR, Sumner DS: Prevalence of asymptomatic carotid disease: result of duplex scanning in 348 unselected volunteers. J Vasc Surg 8: 674-678, 1988

5] Conomy JP, Kellermeyer RW: Delayed cerebrovascular consequences of therapeutic radiation. A clinicopathological study of a stroke associated with radiation-related carotid arteriopathy. Cancer 36: 1702-1708, 1975

6] Elerding SC, Fernandez RN, Grotta JC, Lindberg RD, Causay LC, McMurtrey MJ: Carotid artery disease following external cervical irradiation. Ann Surg 194: 609-615, 1981

7) Fonkalsrud EW, Sanchez M, Zerubavel R, Mahoney A: Arterial endothelial changes following ischemia and perfusion. Surg Gynecol Obstet 142: 715, 1976

8) Fonkalsrud EW, Sanchez M, Zerubavel R, Mahoney A: Serial changes in arterial structure following radiation therapy. Surg Gynecol Obstet 145: 395-400, 1977

9) Freitag G, Freitag J, Koch RD, Wagemann W: Percutaneous angioplasty of carotid artery stenoses. Neuroradiology 28: 126-127, 1986

10) Glick B: Bilateral carotid occlusive disease following irradiation for carcinoma of the vocal cords. Arch Path 93: 352-355, 1972

11) Hyward RH: Arteriosclerosis induced by radiation. Surg Clin North Am 52: 359-366, 1972

12) Kearsley JH: Late cerebrovascular disease after radiation therapy: Report of two cases and a review of the literature. Australas Radiol 27: 11-18, 1983

13) Kerber CW, Cromwell LD, Loehden OL: Catheter dilatation of proximal carotid stenosis during distal bifurcation endarterectomy. AJNR Am J Neuroradiol 1: 348-349, 1980

14) Levinson SA, Close MB, Ehrenfeld WK, Stoney RJ: Carotid artery occlusive disease following external cervical irradiation. Arch Surg 107: 395-397, 1973

15) Moritz MW, Higgius RF, Jacobs JR: Duplex imaging and incidence of carotid radiation injury after highdose radiotherapy for tumors of the head and neck. Arch Surg 125: 1181-1183, 1990

16) Mullan S, Duda EE, Patronas NJ: Some examples of balloon technology in neurosurgery. J Neurosurg 52: 321-329, 1980

17) Ramsey $D E$, Miles RD, Lambeth A, Sumner DS: Prevalence of extracranial carotid artery disease. A survey of an asymptomatic population with noninvasive techniques. J Vasc Surg 5: 584-588, 1987

18) Rubin P, Casarett GW: Radiation histopathology of small blood vessels, in: Clinical Radiation Pathology, vol 1. Philadelphia, WB Saunders, 1968, pp 46-51

19) Sams A: Histological changes in the larger blood vessels of the hind limb of the mouse after $x$-irradiation. Int J Radiat Biol 9: 165-174, 1965

20) Silverberg GD, Britt RH, Goffinet DR: Radiation-induced carotid artery disease. Cancer 41: 130-137, 1978

21) Smith RR: Comment on Atkinson JLD, Sundt TM Jr, Dale AJD, Cascino TL, Nichols DA: Radiation-associated atheromatous disease of the cervical carotid artery: Report of seven cases and review of the literature. Neurosurgery 24: 178, 1989

22) Theron J, Raymond J, Casasco A, Courtheoux F: Per- 
cutaneous angioplasty of atherosclerotic and postsurgical stenosis of carotid arteries. AJNR Am J Neuroradiol 8: 495-500, 1987

23) Tsai FY, Matovich V, Hieshima G, Shah DC, Mehringer CM, Tiu G, Higashida R, Pribram HFW: Percutaneous transluminal angioplasty of the carotid artery. AJNR Am J Neuroradiol 7: 349-358, 1986
Address reprint requests to: K. Nishi, M.D., Department of Neurological Surgery, School of Medicine, The University of Tokushima, 3-18-15 Kuramoto-cho, Tokushima 770, Japan. 